\title{
'Branqueamento' do Brasil
}

\section{The 'whitening' of Brazil}

\author{
Ricardo Augusto dos Santos \\ Casa de Oswaldo Cruz / Fundação Oswaldo Cruz \\ raugusto@coc.fiocruz.br
}

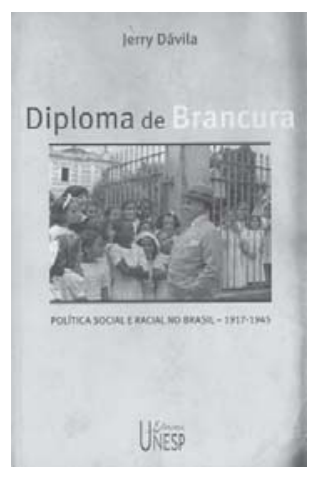

Dávila, Jerry. Diploma de brancura: política social e racial no Brasil 1917-1945.

São Paulo: Ed. Unesp 2005. 400p.
$\Lambda^{\text {tuan }}$ tualmente ocorre um debate intelectual e político sobre as políticas de promoção à igualdade racial, em especial, sobre a implantação de cotas nas universidades. Um número razoável de artigos tem surgido em revistas científicas e jornais diários, procurando justificar as opiniões em confronto. Partidários das iniciativas de inclusão social defendem a maior representação dos negros na sociedade mediante o ingresso no ensino superior através de cotas. Para eles, as políticas de ação afirmativas seriam respostas às desigualdades históricas vividas por tais grupos. De outro lado, observamos argumentos que criticam essas medidas por estimularem a 'racialização' da sociedade brasileira e, no limite, o próprio racismo. Os partidários desta perspectiva argumentam que mudanças na qualidade do ensino básico e médio e/ou cotas por critérios socioeconômicos poderiam propiciar o acesso de jovens pobres de origens étnicas diversas à educação de qualidade e, conseqüentemente, a melhores condições de vida. Argumentos históricos têm sido buscados

por ambos os lados, e o livro Diploma de brancura, agora editado em português, desempenha um importante papel nesse debate.

Nesse livro, o historiador porto-riquenho Jerry Dávila, além de contribuições - mesmo que involuntárias - ao debate mencionado, faz um relevante estudo das políticas de educação do Brasil entre 1917 e 1945, quando esta foi valorizada pelo ideário eugênico, para a construção da nação brasileira. Dávila esmiúça a influência que a eugenia exerceu no pensamento social brasileiro e como ela orientou a política educacional, marcando o cotidiano nas escolas do Rio de Janeiro na primeira metade do século passado. Nos seis capítulos que compõem a obra, encontramos uma profícua análise das instituições e dos intelectuais empenhados em projetos que visavam tornar as escolas públicas acessíveis aos brasileiros pobres e não-brancos. Entre os atores analisados estão alguns intelectuais daquele tempo: Anísio Teixeira, Francisco Campos, Gustavo Capanema, Afrânio Peixoto e Fernando de Azevedo.

O texto demonstra que no período entre as duas grandes guerras buscou-se formar indivíduos saudáveis, produtivos e plenamente integrados, numa reação às concepções deterministas que influenciaram os pensadores brasileiros, fazendo-os acreditar que a população brasileira, em sua maioria, era constituída por homens degenerados, indolentes, analfabetos e doentes. Assim, Dávila argumenta que as décadas iniciais do século passado foram marcadas pelo esforço 
de muitos intelectuais em divulgar a eugenia, então considerada como um antídoto para os males do país, através da publicação de livros e panfletos e da organização de associações e congressos. A eugenia teria sido, então, uma tentativa científica de aprimorar os indivíduos por meio do melhoramento de seus traços genéticos. Segundo as teorias racistas que associavam degeneração à miscigenação, a união de indivíduos de etnias diferentes produzia incapazes, degenerados, indolentes, ou mesmo com tendências para a criminalidade. Isto porque, segundo os partidários da teoria da degeneração racial, os mestiços recebiam traços diversos e mesmo antagônicos dos seus pais de raças diferentes. Portanto, essa herança racial entrava em conflito ao se miscigenar, produzindo indivíduos instáveis e incapacitados para a vida civilizada, que exigia disciplina, trabalho e ordem. Dávila argumenta que, diante dessa interpretação pessimista do país, uma ciência que prometia aperfeiçoar a raça nacional logo alcançaria prestígio: o pessimismo em relação ao perfil racial nacional poderia ser superado quando as práticas do eugenismo fossem adotadas. Percebida como uma arma capaz de melhorar a raça e o futuro do Brasil, a eugenia encontrou entre educadores e médicos seus mais importantes divulgadores.

Como poderíamos construir uma nação moderna diante desse quadro tão desalentador, em que a miscigenação de raças era elemento explicativo para a nossa miséria? Tínhamos um território potencialmente rico, mas ainda não éramos uma nação. Esta era a perspectiva hegemônica no pensamento social brasileiro até a década de 1910. No entanto, essa visão determinista e negativa sobre o Brasil sofreria mudanças. Como se explica tal reorientação? Que interpretação auxiliou a repensar o 'improdutivo' homem brasileiro? Uma expedição científica que dois médicos lideraram pelos 'abandonados sertões' do Brasil constituiu verdadeira inflexão sobre o diagnóstico do país. A viagem de Belisário Penna e Arthur Neiva aos rincões desconhecidos dos sertões e o impacto causado pela publicação do relatório dessa viagem, em 1916, ajudaram a transformar o paradigma interpretativo dominante. A esse respeito, Dávila corretamente atribui um peso considerável à repercussão da epopéia de Penna e Neiva para a revelação dos problemas do Brasil (p.58). Segundo o historiador, dos médicos sanitaristas, ao negarem as teses da indolência inata do brasileiro, vinha o remédio para o futuro promissor: a educação higiênica e as ações públicas sanitárias. Afinal, os homens encontrados por Penna e Neiva nos locais mais recônditos do país, se não eram uma plêiade de valorosos guerreiros, tampouco constituíam uma massa humana não aproveitável.

Cotejando o pensamento social e político brasileiro, o professor da Universidade da Carolina do Norte (EUA) comenta com sucesso o emaranhado de teorias que buscavam explicar a real condição do 'homem brasileiro'. Reorganizando as idéias que associavam a herança negra à degeneração, médicos, educadores e formuladores de políticas públicas passaram a considerar que, com reformas na saúde e na educação, poder-se-ia fugir da determinação biológica, que afirmava peremptoriamente a inferioridade nacional, e constituir uma raça saudável e um Brasil alinhado com o progresso. Como? Substituindo a noção de 'degeneração herdada' pela de 'degeneração adquirida' e, portanto, remediável ou, ao menos, mitigada.

Dávila afirma que os eugenistas brasileiros se diferenciavam dos eugenistas de outros países no grau em que levavam as idéias e práticas eugenistas para fora do laboratório e para dentro das políticas públicas (p.55). Portanto, o autor não ignora a originalidade da eugenia em terras brasileiras. Indubitavelmente, no Brasil, coexistiam teorias que adotavam uma seleção racial capaz de embranquecer a população, produzindo um tipo nacional pelas sucessivas 
miscigenações, com teses de que o futuro eugênico seria resultado também do aperfeiçoamento das políticas públicas de saúde e educação. Seguindo a perspectiva neolamarckista, que aceitava a influência do ambiente na transmissão de características hereditárias, médicos e educadores entendiam que as reformas sanitárias aprimorariam a capacidade eugênica. Por exemplo, eles acreditavam que campanhas contra o alcoolismo e as doenças venéreas melhorariam a 'raça nacional'. As condições do meio deveriam modificar-se para que, transformando os indivíduos, os seus descendentes fossem beneficiados. A eugenia brasileira, além de produzir homens saudáveis, pretendia também recuperar os degenerados e, conseqüentemente, 'salvar' a nação.

Para tratar os produtos da degeneração racial, intelectuais e cientistas eugenistas valiam-se da eugenia preventiva, positiva e negativa. A primeira, responsável por promover a higiene individual, a educação e o saneamento do país. Julgando que a modificação das condições ambientais levaria a uma capacidade genética superior, e que esta seria transmitida aos descendentes, tal visão influenciou as políticas públicas no Brasil. Um bom exemplo são as atividades esportivas: durante o Estado Novo (1937-1945), foi muito difundida a prática da educação física nas escolas. Já a eugenia negativa visava eliminar os seres imperfeitos que, por exemplo, através da esterilização compulsória, seriam condenados a não gerarem descendentes. Esta perspectiva negativa da eugenia não prosperou no Brasil, ao contrário do que fez em outras terras como a Alemanha nazista e os próprios Estados Unidos.

O objetivo de branquear a sociedade teria êxito, a partir da promoção de condições favoráveis à procriação eugênica através da educação, da higiene e do combate à reprodução dos degenerados e criminosos, porque estes poderiam transmitir os defeitos morais, físicos e mentais aos descendentes. Também encontramos políticas eugênicas nas propostas para que o Estado adotasse medidas profiláticas para o controle das enfermidades que beneficiavam os fatores disgênicos (degenerativos) da sociedade, como a sífilis, a tuberculose e o alcoolismo. Em relação a este aspecto, Dávila adota uma distinção - muito presente nas pesquisas - entre os eugenistas 'leves', que aceitavam a melhoria racial por meio da atenção à saúde pública, às influências ambientais e aos valores culturais, e os 'pesados', que propunham a eliminação de características degeneradas por meio do controle estrito da reprodução humana: "Os eugenistas 'leves' aceitavam a melhoria racial por meio da atenção à saúde, influências ambientais, valores culturais e circunstâncias de reprodução. Os eugenistas 'pesados' não aceitavam a modificação de traços, e se concentravam na eliminação de traços indesejáveis por meio do controle da reprodução" (p.53).

Identificado o baixo nível educacional do país como causa da pobreza e das doenças, uma proposta para superar os obstáculos que dificultavam a entrada do Brasil na civilização momento da evolução que os outros países experimentavam - seria a difusão da educação. Pretendeu-se fazer da escola, portanto, o centro irradiador da moderna nação. E regenerar a raça nacional pela educação passou a ser um dos pilares do discurso eugênico, que entendia ser necessário instruir o povo, pois somente a educação conduziria o país à condição de nação moderna. Todavia, Dávila argumenta que, mesmo com a absorção dos negros nas escolas, a ascensão social dos afro-descendentes e membros das classes populares não ocorreu. O historiador porto-riquenho explica o fato demonstrando que embora participantes na educação pública, os alunos pobres e mestiços foram tratados pelo sistema educacional como deficientes. $\mathrm{O}$ autor afirma que esses alunos não foram excluídos, receberam dos administradores da 
educação pública a oportunidade de participar da expansão educacional ocorrida nas primeiras décadas do século XX. Mas, paradoxalmente, pobres e não-brancos teriam sofrido constrangimentos que limitaram sua presença nas escolas, reproduzindo a posição subordinada dos negros e mestiços na sociedade brasileira.

Dávila argumenta que houve uma reorganização de estratégias mantenedoras da distância social entre as 'raças', impedindo que a desigualdade fosse alterada, ainda que procedimentos para a superação das barreiras tenham sido criados. Neste ponto, merece destaque a análise de Dávila sobre os testes psicológicos. Ele explica que os procedimentos para aferir capacidades de aprendizagem ficaram diluídos numa política de isolamento racial. De antemão, esperavase um mau desempenho das crianças das camadas populares. Por meio desses medidores de inteligência, como a Escala de Binet (também chamada de Teste de Q.I.), eram atribuídas distinções entre os alunos, estabelecendo rótulos como 'não inteligente', 'rebelde' ou 'imaturo'. Acabava-se perpetuando e institucionalizando pressupostos de raça e classe. Para Dávila as políticas escolares integravam e segregavam ao mesmo tempo. Para ele, isto era uma incongruência porque reforçava diferenças inerentes à hereditariedade.

Escrito de forma acessível, embora tenha como alvo especialistas das ciências humanas, o livro merece e deve ser lido por um público mais amplo interessado não apenas em entender a eugenia brasileira mas também o debate contemporâneo sobre as relações raciais no Brasil.

\section{$\rightarrow \rightarrow *<<<$}

